\title{
Liquidity Traps with Global Taylor Rules*
}

\author{
Stephanie Schmitt-Grohé ${ }^{\dagger}$ \\ Rutgers University and CEPR
}

\author{
Martín Uribe $\ddagger$ \\ University of Pennsylvania
}

July 24,2000

\begin{abstract}
A key result of a recent literature that focuses on the global consequences of Taylortype interest rate feedback rules is that such rules in combination with the zero bound on nominal interest rates can lead to unintended liquidity traps. An immediate question posed by this result is whether the government could avoid liquidity traps by ignoring the zero bound, that is, by threatening to set the nominal interest rate at a negative value should the inflation rate fall below a certain threshold. This paper shows that even if the government could credibly commit to setting the interest rate at a negative value, self-fulfilling liquidity traps can still emerge. That is, deflationary equilibria originating arbitrarily near the intended equilibrium and leading to low (possibly zero) interest rates and low (and possibly negative) rates of inflation cannot be ruled out by lifting the zero bound on the monetary policy rule. This result obtains in models with flexible and sticky prices and under continuous and discrete time.
\end{abstract}

JEL Classification Numbers: E52, E31, E63.

Keywords: Taylor rules, liquidity traps, zero bound on nominal interest rates.

${ }^{*}$ We would like to thank Jess Benhabib and Bill Dupor for very helpful discussions.

†Phone: 732932 2960. Email: grohe@econ.rutgers.edu.

†Phone: 215898 6260. Email: uribe@econ.upenn.edu. 


\section{Introduction}

A growing recent literature in macroeconomics stresses the consequences of interest rate feedback rules for aggregate stability. One reason for the renewed interest in this type of monetary policy rule is empirical. Since the influential work of Taylor (1993), a number of authors has documented that in the post-Volker era U.S. monetary policy is well described by a feedback rule whereby the nominal interest rate is set as an increasing function of inflation and the output gap. ${ }^{1}$ Indeed, interest rate rules have been found to be a good representation of actual monetary policy in the largest developed economies (Clarida, Galí, and Gertler, 1998).

Theoretically, the appeal of interest-rate feedback rules is founded on the argument that active interest-rate rules, or Taylor rules, are conducive to macroeconomic stability. Active interest rate rules are those that stipulate an inflation coefficient larger than unity. ${ }^{2}$ Active interest-rate rules are also known as Taylor rules after Taylor's (1993) study of monetary policy in the United States. In the context of a flexible-price model, Leeper (1991) shows that active interest rate rules are stabilizing in the sense that they ensure uniqueness of the rational expectations equilibrium. ${ }^{3}$ A similar result has been derived in models with nominal rigidities by Clarida, Galí, and Gertler (1997) and Woodford (1996). Active interest-rate rules have also been advocated on the grounds that they minimize the variability of output and inflation. For example, Levin, Wieland, and Willams (1999) show, in the context of an ad-hoc model, that Taylor-type rules minimize a loss function that is quadratic in deviations of inflation and output from target. Rotemberg and Woodford (1999) obtain a similar result using a utility maximizing model and a welfare criterion for evaluating monetary policy.

A common element present in the body of work described above is its focus on local dynamics around the intended, or target, steady-state equilibrium. Benhabib, SchmittGrohé, and Uribe (2000b) argue that this local approach leaves in obscurity a number of important macroeconomic consequences of Taylor rules. Specifically, they point out that if the interest rate feedback rule is assumed to respect the zero bound on nominal rates, then there emerges a second (unintended) steady state. In this steady state, inflation is low and possibly negative and the nominal interest rate is below target and possibly zero. More importantly, they show that the rational expectations equilibrium is no longer unique. In particular, there exist deflationary spirals connecting the target steady state with the

\footnotetext{
${ }^{1}$ See, for example, Sack (1998), Orphanides (1997), Clarida, Galí, and Gertler (1997), and Taylor (1999).

${ }^{2}$ The term 'active' in referring to monetary policy was introduced by Leeper (1991).

${ }^{3} \mathrm{~A}$ requirement for Leeper's result to hold is that fiscal policy be passive, that is, that it guarantee that the government's intertemporal budget constraint be satisfied under all possible (local) paths of the price level.
} 
Figure 1: The zero bound and multiple steady-state equilibria

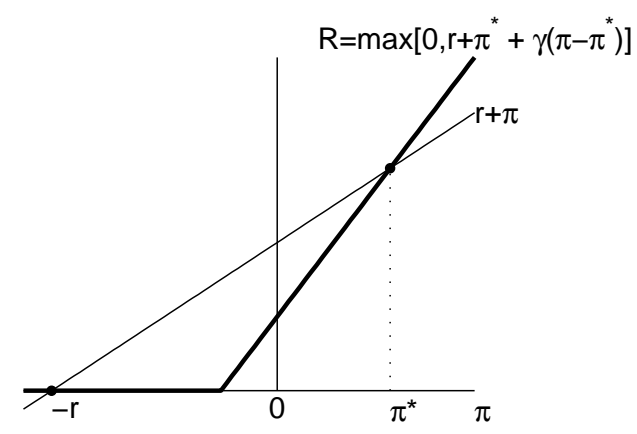

unintended one.

The consequences of the zero lower bound on nominal rates for the number of steadystate equilibria can be conveyed by means of two basic relationships: one is the steady-state Fischer equation $R=r+\pi$, where $R$ denotes the nominal interest rate, $\pi$ denotes the rate of inflation, and $r$ denotes the real interest rate. The other relationship is a non-negative interest rate feedback rule like the piecewise linear function $R=\max \left[0, r+\pi^{*}+\gamma\left(\pi-\pi^{*}\right)\right]$, where $\pi^{*}$ denotes the target rate of inflation and $\gamma$ is a parameter greater than one. Figure 1 plots both relationships. One solution to these two equations is $\pi=\pi^{*}$ and $R=R^{*} \equiv r+\pi^{*}$. At the inflation rate $\pi^{*}$ monetary policy is active because $\gamma>1$.

Most of the existing related literature that advocates the use of Taylor rules has been build on the result that under plausible economic environments the intended steady state $\left(\pi^{*}, R^{*}\right)$ is locally the unique rational expectations equilibrium. ${ }^{4}$ But the two equations plotted in figure 1 admit another solution, $\pi=-r$ and $R=0$. The emergence of this second steady state is a direct consequence of the imposed zero bound on the nominal interest rate. At the low inflation steady state monetary policy is passive. Benhabib, SchmittGrohé and Uribe (2000b) show that around this steady state, the rational expectations equilibrium is indeterminate. Moreover, Benhabib, Schmitt-Grohé and Uribe show that there exist equilibrium trajectories originating arbitrarily close to the target steady state that converge to the unintended steady state. They argue that these equilibrium dynamics have the essential characteristics of liquidity traps. For they represent situations in which the economy embarks on a deflationary path, which the monetary authority is unable to

\footnotetext{
${ }^{4}$ However, a number of recent papers call into question the plausibility of local stability under active interest rate rules. For example, Benhabib, Schmitt-Grohé and Uribe (2000a) show that local uniqueness of equilibrium under active interest-rate rules depends on preference and technology specifications. Dupor (1999) shows that in production economies with sticky prices active interest-rate rules lead either to the inexistence or the indeterminacy of local equilibria. Carlstrom and Fuerst (2000) show that in models with capital and flexible prices active forward-looking interest rate rules render the equilibrium locally indeterminate.
} 
Figure 2: A globally valid Taylor rule

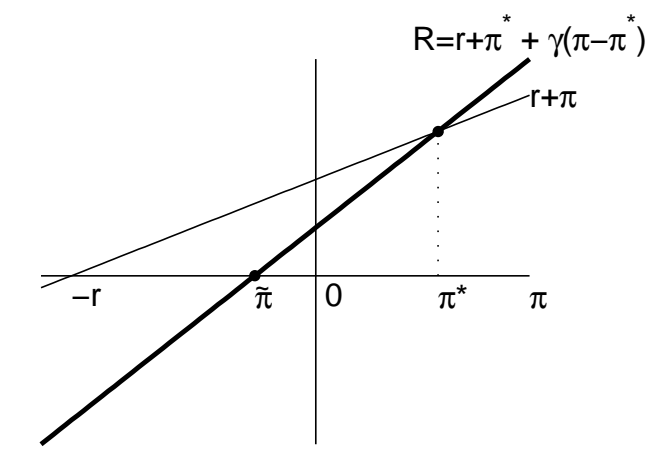

stop in spite of its repeated efforts to inflate the economy through aggressive cuts in interest rates.

The above discussion makes it clear that it is the imposition of a zero bound on nominal rates that opens the door to a second, undesired steady state and to the possibility of selffulfilling liquidity traps. It is therefore natural to ask whether the removal of the zero bound on nominal rates would eliminate the low-inflation steady state and with it the undesired liquidity trap equilibria. This question is the central focus of the present study.

Continuing with the linear example given above, the lifting of the zero bound on the interest rate rule results in a globally active rule of the form $R=r+\pi^{*}+\gamma\left(\pi-\pi^{*}\right)$. The interest rate feedback rule and the steady-state Fisher equation then have a unique solution given by the intended steady state $\pi=\pi^{*}$ and $R=R^{*}$ (see figure 2). Perhaps the most important difficulty with assuming the global validity of the Taylor criterion is that in reality governments may not be able to credibly commit to it. If the inflation rate falls within the range for which the rule stipulates a negative interest rate, the central bank would most likely not be willing to implement the prescribed policy. For in this case, an arbitrage opportunity would arise allowing private agents to make unbounded profits on account of the government. ${ }^{5}$

In this paper, we do not take a position on whether governments can credibly commit to globally active interest rate rules or not. Rather, we ask whether, assuming that the monetary authority can indeed maintain a global Taylor rule, equilibrium liquidity traps are still possible. We find that the answer is yes. In the context of standard monetary models, we show that if the Taylor rule takes the form shown in figure 2, then there exists a continuum of rational expectations equilibria in each of which the nominal interest rate converges asymptotically to zero and the inflation rate converges to a constant greater than

\footnotetext{
${ }^{5}$ This lack-of-credibility argument is of the same nature as that put forth by those who question the logical possibility of non-Ricardian fiscal policy in the context of the fiscal theory of price level determination (e.g., Buiter, 1998, 1999).
} 
$-r$ (labeled $\tilde{\pi}$ in figure 2). These are liquidity traps in which the economy converges to a situation that does not represent a steady state. In particular, in the limiting state of the economy the steady state Fisher equation is not satisfied. This result is of particular interest because it establishes that the possibility of self-fulfilling liquidity traps under Taylor rules is not necessarily the consequence of the presence of a second steady state induced by the zero bound on nominal rates.

We begin by demonstrating the existence of liquidity traps under global Taylor rules using a simple continuous-time, flexible-price, money-in-the-utility-function model. This task is accomplished in sections 2 and 3. Section 3 also contains two important extensions. Subsection 3.2 shows that liquidity traps may not exist under two particular preference specifications: when consumption and real balances enter the utility function in an additively separable fashion and when the instant utility index exhibits satiation in real balances. The latter case is particularly relevant because it comprises the class of cash-in-advance models with cash-and-credit goods introduced by Lucas and Stokey (1987). Subsection 3.3 demonstrates that the possibility of liquidity traps under globally active interest-rate rules is robust to assuming that time is a discrete variable.

In section 4, we consider a more realistic environment with endogenous labor supply, production, and sluggish price adjustment a là Rotemberg (1982). We show that, as in the endowment, flexible-price economy, self-fulfilling liquidity traps arise despite the fact that the interest rate feedback rule is globally active. Finally, section 5 present some concluding remarks.

\section{The model}

In this section we use a simple economic environment to illustrate how a monetary-fiscal regime frequently advocated on the basis of aggregate stability can in fact lead to expectational traps. The difference between our analysis and that found in the related literature is twofold: first, we do not restrict the analysis to local dynamics around a particular station-

ary state. Second, we assume that the central bank follows a globally active interest rate feedback rule. As a consequence, the central bank commits to set negative nominal rates for sufficiently low rates of inflation.

\subsection{Households}

Consider an endowment economy populated by a large number of identical infinitely lived households with preferences defined over consumption and real balances and described by 
the utility function

$$
\int_{0}^{\infty} e^{-r t} u(c, m) d t
$$

where $r>0$ denotes the subjective rate of time preference, $c$ denotes consumption, $M$ denotes nominal money balances, and $P$ denotes the price level. The instantaneous utility index $u$ is assumed to be increasing in both arguments, concave, and to satisfy $u_{c m}>0$, so that consumption and real balances are Edgeworth complements. We also assume that

$$
\lim _{m \rightarrow \infty} u_{c}(c, m)=\infty \quad \forall c>0
$$

and that

$$
\lim _{m \rightarrow \infty} \frac{u_{m}(c, m)}{u_{c}(c, m)}=0 \quad \forall y>0
$$

This last assumption implies that money demand approaches infinity as the nominal interest rate vanishes. All of the above assumptions are satisfied, for example, when the instant utility function takes the CRRA/CES form

$$
u(c, m)=\frac{\left[a c^{\rho}+(1-a) m^{\rho}\right]^{(1-\sigma) / \rho}}{1-\sigma}
$$

with $a \in(0,1), \sigma \geq 0$, and $\rho<1$.

In addition to fiat money, the representative household has access to nominal government bonds, denoted by $B$, that pay the nominal interest rate $R$. The household is endowed with a constant stream of perishable goods $y$ and pays real lump-sum taxes $\tau$. Its instant budget constraint is then given by

$$
P c+P \tau+\dot{M}+\dot{B}=R B+P y \text {. }
$$

Letting $m \equiv M / P$ denote real balances and $a \equiv(M+B) / P$ real financial wealth, the above constraint can be written as

$$
c+\tau+\dot{a}=(R-\pi) a-R m+y,
$$

where $\pi \equiv \dot{P} / P$ denotes the instant rate of inflation. The right-hand side of this budget constraint represents the sources of income: real interest on the household's assets net of the opportunity cost of holding money and the endowment. The left hand side shows the uses 
of income: consumption, tax payments, and savings. Households are subject to a borrowing limit of the form

$$
\lim _{t \rightarrow \infty} e^{-\int_{0}^{t}[R(s)-\pi(s)] d s} a(t) \geq 0
$$

that prevents them from engaging in Ponzi games. This no-Ponzi-game constraint says that the household is not permitted to implement consumption and money-holding plans that imply that its real debt position net of money holdings grows at a rate higher than or equal to the real interest rate. Clearly, because the utility function is increasing in consumption and real balances, the household will always find it optimal to satisfy the above borrowing limit with equality.

The representative household chooses paths for consumption, real balances, and wealth so as to maximize (1) subject to the instant budget constraint (5) and the borrowing limit (6), given its initial real wealth, $a(0)$, and the paths of taxes, inflation, and nominal interest rates. The associated optimality conditions are (5), (6) holding with equality, and

$$
\begin{gathered}
u_{c}(c, m)=\lambda \\
u_{m}(c, m)=\lambda R \\
\frac{\dot{\lambda}}{\lambda}=r+\pi-R,
\end{gathered}
$$

where $\lambda$ is the Lagrange multiplier associated with the instant budget constraint.

\subsection{Monetary and fiscal policy}

We assume that the monetary authority follows a Taylor-type interest-rate feedback rule of the form

$$
R=r+\pi^{*}+\gamma\left(\pi-\pi^{*}\right)
$$

where $\pi^{*}>-r$ denotes the central bank's inflation target and $\gamma>1$ defines the responsiveness of the interest rate to deviations of inflation from its target. ${ }^{6}$ Loosely speaking, the central bank raises the real interest rate in response to an increase in inflation and lowers it in response to a decrease in inflation. We assume that the central bank adheres to the Taylor criterion $(\gamma>1)$ globally, that is, for all possible rates of inflation. As a consequence, there exists an inflation rate $\tilde{\pi} \equiv \pi^{*}-\left(r+\pi^{*}\right) / \gamma>-r$ such that whenever $\pi<\tilde{\pi}$, the interest rate feedback rule prescribes a negative nominal interest rate. This assumption distinguishes the

\footnotetext{
${ }^{6}$ Leeper (1991) refers to monetary policy as active if $\gamma>1$ and as passive if $\gamma<1$.
} 
analysis of the existence of liquidity traps under interest rate feedback rules presented in this paper from that contained in Benhabib, Schmitt-Grohé, and Uribe (2000b) and Woodford (1999).

The government finances its deficits by printing money, $M$, and issuing nominal bonds, $B$, that pay the nominal interest rate $R$. We assume that public consumption is zero and that the government levies real lump-sum taxes, $\tau$. Therefore, the instant budget constraint of the government is given by $\dot{B}=R B-\dot{M}-P \tau$, which can be written as

$$
\dot{a}=(R-\pi) a-R m-\tau \text {. }
$$

By definition, the initial condition $a(0)$ satisfies

$$
a(0)=\frac{A(0)}{P(0)}
$$

where $A(0) \equiv M(0)+B(0)>0$ denotes the initial level of total nominal government liabilities. We will assume that fiscal policy is Ricardian in the sense of Benhabib, Schmitt-Grohé, and Uribe (2000a). Ricardian fiscal policies are those that ensure that the present discounted value of total government liabilities converges to zero - that is,

$$
\lim _{t \rightarrow \infty} e^{-\int_{0}^{t}[R(s)-\pi(s)] d s} a(t)=0
$$

is satisfied under all possible, equilibrium or off-equilibrium, paths of endogenous variables, such as the price level, the money supply, inflation, or the nominal interest rate. We restrict attention to one particular Ricardian fiscal policy that takes the form

$$
\tau+R m=\alpha a
$$

where the sequence $\alpha$ is chosen arbitrarily by the government subject to the constraint that it is positive and bounded below by some $\underline{\alpha}>0$. This policy states that consolidated government revenues, that is, tax revenues plus interest savings from the issuance of money, are always higher than a certain fraction $\underline{\alpha}$ of total government liabilities.

\section{$2.3 \quad$ Equilibrium}

Equilibrium in the goods market requires that consumption be equal to the endowment

$$
c=y \text {. }
$$


Given the assumptions regarding the form of the instant utility function, equations (7), (8), and (15) define a decreasing function linking $\lambda$ and $R$ :

$$
\lambda=L(R) ; \quad L^{\prime}<0 .
$$

Using this expression to eliminate $\lambda$ from equation (7) yields the following equilibrium Euler equation:

$$
\dot{R}=\frac{L(R)}{L^{\prime}(R)}[r+\pi-R]
$$

Finally, using the feedback rule (10) to eliminate inflation from this expression we obtain a univariate first-order differential equation describing the equilibrium dynamics of the nominal interest rate:

$$
\dot{R}=\frac{(1-\gamma) L(R)}{\gamma L^{\prime}(R)}\left[R-R^{*}\right]
$$

where $R^{*} \equiv r+\pi^{*}$ is the nominal interest rate associated with the target rate of inflation $\pi^{*}$.

In turn, combining the government budget constraint (11) with the monetary and fiscal policy rules, equations (10) and (14), yields

$$
\dot{a}=\left[\left(1-\gamma^{-1}\right)\left(R-R^{*}\right)+r-\alpha\right] a
$$

Finally, using (10) to eliminate $\pi$ from (13), the transversality condition becomes

$$
\lim _{t \rightarrow \infty} e^{-\int_{0}^{t}\left[\left(1-\gamma^{-1}\right)\left(R(s)-R^{*}\right)+r\right] d s} a(t)=0
$$

A perfect-foresight competitive equilibrium is defined as an initial price level $P(0)$ and functions of time $R$ and $a$ satisfying (12) and (18)-(20), given the initial condition $A(0)$. Note that because of the assumed Ricardian nature of the fiscal policy regime, given a function $R$ satisfying (18), equations (12) and (19) imply a path for a that satisfies the transversality condition for any initial $a(0)$. This fact has two implications. First, any nonnegative function of time $R$ satisfying (18) constitutes a perfect-foresight equilibrium, and, second if an equilibrium exists, then the initial price level $P(0)$ is indeterminate. However, nominal indeterminacy is not the focus of our analysis. We are instead concerned with real determinacy, that is, the determinacy of the function $R$, which in turn governs the determination of real balances and thus welfare. 


\section{$3 \quad$ Liquidity traps with global Taylor rules}

Consider first the steady-state solutions to equation (18). Clearly, because $\gamma \neq 1$, there is a unique steady state $R=R^{*}$. The result that the steady-state equilibrium is unique is driven by the assumption that the monetary authority can make it credible that it will follow an active interest rate feedback rule globally. As shown in Benhabib, Schmitt-Grohé, and Uribe (2000b), if instead the interest rate feedback rule is constrained to be non-negative, then a second steady state emerges. This second steady state represents a liquidity trap in sofar that inflation is low and possibly negative and the nominal interest rate is below the target rate.

Because $R$ is a non-predetermined variable, the steady state $R^{*}$ is, in fact, a perfectforesight equilibrium. Furthermore, $R^{*}$ is locally the unique perfect foresight equilibrium. Note that given our maintained assumption that the feedback rule is globally active, $(1-$ $\gamma) / \gamma L(R) / L^{\prime}(R)$ is always positive. This implies that the sign of $\dot{R}$ in equation (18) is the same as the sign of $R-R^{*}$. It follows that the steady state $R^{*}$ is locally unique in the sense that trajectories starting near $R^{*}$ diverge from $R^{*}$. Thus, if one were to limit the analysis to equilibria in which $R$ remains forever in a small neighborhood around $R^{*}$, then the only perfect-foresight equilibrium is the steady state itself. This local uniqueness result has served as a key theoretical argument for advocating the use of active, or Taylor-type, interest-rate feedback rules to ensure aggregate stability (e.g., Leeper, 1991; and Clarida, Galí, and Gertler, 1997).

However, as we show next, $R^{*}$ is not the only perfect-foresight equilibrium. Specifically, we wish to show that under certain assumptions regarding the form of the instant utility function, there exists a continuum of perfect foresight equilibria in each of which $R$ converges to zero. Thus, in each of these equilibria the economy is caught in a expectations driven liquidity trap.

Suppose that the interest rate semi elasticity of the equilibrium marginal utility of consumption becomes unboundedly large as the nominal interest rate approaches zero. Formally, assume that the function $L(\cdot)$ satisfies

$$
\lim _{R \rightarrow 0} \frac{L^{\prime}(R)}{L(R)}=\infty
$$

Given assumption (3), it is straightforward to show that (21) is equivalent to assuming that

$$
\lim _{m \rightarrow \infty} \frac{u_{m m}(y, m)}{u_{c m}(y, m)}=0 .
$$


Figure 3: Phase diagram

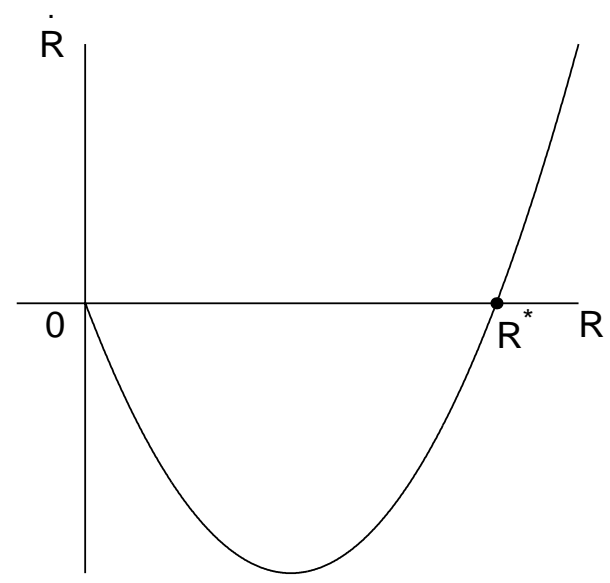

This assumption is satisfied, for example, when the instant utility index takes the form given in (4).

Figure 3 depicts the phase diagram of $R$ implied by equation (18) under assumption (21). Clearly, if the economy starts at $R(0)=R^{*}$, then it remains at the target rate forever. However, if the initial interest rate satisfies $0<R(0)<R^{*}$, then $R$ falls continuously and approaches zero asymptotically. ${ }^{7}$

Trajectories like the one just described posses all the characteristics of a liquidity trap. Namely, inflation is expected to follow a declining spiral. The central bank, in turn, attempts to inflate the economy by lowering the nominal interest rate so aggressively that the real interest rate falls. This continuous decline in the real interest rate induces a declining path in desired consumption. But because aggregate supply is fixed, the equilibrium response is a further decline in prices.

\subsection{The dynamics of money, wealth, taxes, and inflation}

Because the linear Taylor rule is assumed to hold globally, inflation is linearly linked to the nominal interest rate along the entire deflationary spiral. Thus, $\pi$ decreases monotonically and converges asymptotically to $\tilde{\pi}$. The declining path of the nominal interest rate is accompanied by less than one-to-one declines in inflation. As a result, the real interest rate, given by $R-\pi$, decreases monotonically and converges to $-\tilde{\pi}$, which may be positive or negative depending on the values taken by $\gamma, \pi^{*}$, and $r$.

Given assumption (3), real balances become unboundedly large as the nominal interest rate vanishes. At the same time, the asymptotic evolution of total government liabilities is

\footnotetext{
${ }^{7}$ It is worth noting that $R=0$ does not represent a steady-state equilibrium, for at that level of interest rates real balances cease to be finite.
} 
Figure 4: Time path of key variables
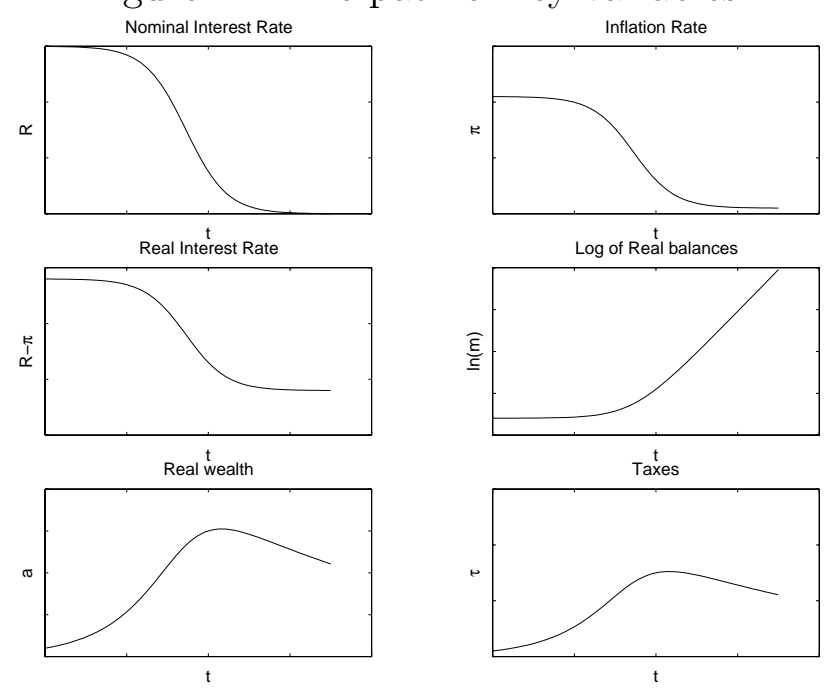

given by $\dot{a}=-(\tilde{\pi}+\alpha) a$. So $a$ converges to zero if $-\tilde{\pi}-\alpha<0$ and to infinity otherwise. In particular, if the long-run inflation rate $\tilde{\pi}$ is nonnegative, total government liabilities vanish asymptotically. Because real money balances grow without bounds, it follows if $a$ converges to zero, then increases in the money supply are brought about through open market operations. In the long run the stock of government bonds becomes negative and unboundedly large in real terms. ${ }^{8}$ Note that if total government liabilities converges to zero, then asymptotically the government rebates all seigniorage revenue through lump-sum transfers, $\tau=-R m$. In turn, the evolution of seignorage revenue depends exclusively on the specification of preferences. Specifically, $m R=m u_{m}(y, m) / u_{c}(y, m)$. So for example, if $u(c, m)=(1-\sigma)^{-1}\left[a c^{\rho}+(1-a) m^{\rho}\right]^{(1-\sigma) / \rho}$, then $m R$ is proportional to $m^{\rho}$. In the CobbDouglas case, $\rho=0$, lump-sum transfers are constant in the long-run. If the elasticity of substitution between real balances and consumption is less (greater) than unity, $\rho<(>) 0$, then lump-sum transfers converge to zero (infinity). Figure 4 depicts the dynamics of the nominal interest rate, inflation, the real interest rate, real wealth, real balances, and real lump-sum taxes for the case of Cobb-Douglas preferences

\subsection{Separability and satiation}

Thus far we have shown that when the Taylor criterion holds globally, the possibility of liquidity traps emerges under a wide range of preference specifications. Preferences in this class include, but are not limited to, the family of instant utility functions given in equation (4).

One commonly used preference specification under which liquidity traps are impossible

\footnotetext{
${ }^{8}$ Indeed, the stock of bonds becomes negative in finite time.
} 
is one in which the instant utility index is additively separable in consumption and real balances. To see why, note that in this case the marginal utility of consumption depends only on consumption and thus is constant in equilibrium. It then follows from equation (7) that the equilibrium value of $\lambda$ is constant. Thus, by the Euler equation (9), we have that in equilibrium $R=r+\pi$. Combining this expression with the Taylor rule (10), we obtain the unique and constant equilibrium interest rate $R^{*}$.

It is important to note, however, that the impossibility of liquidity traps under additive separability in preferences is unrelated to the assumption that the Taylor criterion holds globally. Rather, the uniqueness of equilibrium is a consequence of the fact that under separable preferences the marginal utility is constant over time. ${ }^{9}$ Interestingly, in discrete time liquidity traps arise under separability provided the feedback rule respects the zero bound on nominal rates (Woodford 1999, 2000). But, as we show in the next section, this type of equilibrium is impossible in discrete time if the feedback rule is active everywhere.

Liquidity traps may also be impossible when preferences display satiation in real balances. An example of an environment in which satiation occurs naturally, is the cash-in-advance model with cash and credit goods of Lucas and Stokey (1987). In this economy, households have preferences defined over consumption of cash and credit goods, $c^{1}$ and $c^{2}$, respectively. Suppose for simplicity that the instant utility function is of the form $\ln c^{1}+\zeta \ln c^{2}$. Consumption of the cash good is subject to a cash-in-advance constraint of the form $m \geq c^{1}$. In turn, consumption is subject to the resource constraint $c^{1}+c^{2}=y$, where $y>0$ is an exogenous and constant endowment. This constraint implies a unit relative price of $c^{1}$ in terms of $c^{2}$. The budget and borrowing constraints faced by the household are (5) and (6), with $c \equiv c^{1}+c^{2}$. It is straightforward to show that the optimization problem of the representative household in this economy is identical to that of the representative household in a money-in-the-utility-function economy with instant utility given by

$$
u(c, m)=\left\{\begin{array}{cl}
\ln m+\zeta \ln (c-m) & \text { if } m<m^{*} \\
\ln m^{*}+\zeta \ln \left(c-m^{*}\right) & \text { if } m \geq m^{*}
\end{array},\right.
$$

where $m^{*} \equiv y /(1+\zeta) .^{10}$

Consider first the existence of liquidity traps in which the nominal interest rate is positive but converges asymptotically to zero. Combining the first-order conditions (7) and (8) and

\footnotetext{
${ }^{9}$ Benhabib, Schmitt-Grohé, and Uribe (2000b) discuss the case of separable preferences assuming that the monetary authority's interest rate feedback rule satisfies the non-negativity constraint.

${ }^{10}$ The satiation point $m^{*}$ is given by $\operatorname{argmax}_{c^{1}}\left[\ln c^{1}+\zeta \ln \left(y-c^{1}\right)\right]$.
} 
replacing $c$ by $y$ yields the following equilibrium money demand function:

$$
\frac{y-(1+\zeta) m}{\zeta m}=R
$$

In deriving this liquidity preference function we are using the fact that if $R>0$, then $m<m^{*}$. It follows from this expression that as $R$ vanishes, real money balances converge to $m^{*}$. The evolution of the nominal interest rate is given by equation (18). Thus, as in the case of no satiation, the existence of a liquidity trap requires that assumption (21) is satisfied. Under satiation, assumption (21) is no longer equivalent to (22) but instead to

$$
\lim _{m \rightarrow m^{*}} \frac{u_{m m}(y, m)}{u_{c m}(y, m)}=0
$$

Using the utility function (23) and taking into account that when $R>0, m<m^{*}$, we have

$$
\frac{u_{m m}(y, m)}{u_{c m}(y, m)}=-(1+\zeta)
$$

which clearly does not converge to zero as real balances converge to the satiation point $m^{*}$. Therefore, in this economy, liquidity traps in which the nominal interest rate is positive but converges to zero are impossible.

It remains to establish that liquidity traps in which $R$ reaches zero in finite time are also impossible. If $R=0$, then the Euler equation (9) is violated. To see why, note that if $R=0$, then $m \geq m^{*}$. Thus, $\lambda=u_{c}\left(y, m^{*}\right)$ is positive and constant, so the left hand side of (9) is zero. On the other hand, the right hand side of (9) becomes $r+\tilde{\pi}$, which is different from zero.

We close this section by noting that if the (linear) Taylor rule (10) is required to satisfy the zero bound-so that $R=\max \left\{0, r+\pi^{*}+\gamma\left(\pi-\pi^{*}\right)\right\}$ - then liquidity traps exist when preferences exhibit satiation like in equation (23). In these economies, liquidity traps are characterized by interest rate dynamics that reach the value of zero in finite time. Benhabib, Schmitt-Grohé, and Uribe (2000c) analyze this case in an economic environment like the one presented here (see in particular the appendix). Schmitt-Grohé and Uribe (2000) derive the result in a discrete-time model. ${ }^{11}$

\footnotetext{
${ }^{11}$ Schmitt-Grohe and Uribe (2000) conduct the analysis under the assumption that the government follows a balanced-budget rule. They show that linear Taylor rules that satisfy the zero bound may lead to dynamics in which the economy perpetually fluctuates between two states. In one the interest rate converges to a strictly positive value. In the other the economy falls into a liquidity trap with a zero nominal interest rate. See proposition 3 and in particular the case illustrated in the bottom right panel of figure 3 . The result that liquidity traps cannot last forever (i.e., $R_{t}=0$ for all $t$ cannot be supported as a steady-state equilibrium) is a consequence of the assumed balanced-budget requirement.
} 


\subsection{Discrete Time}

The objective of this subsection is to briefly show that the basic result that liquidity traps exist when the Taylor criterion is valid globally is robust to assuming that time is a discrete variable. To this end, let the utility function take the form $\sum_{t=0}^{\infty} \beta^{t} u\left(c_{t}, m_{t}\right)$, with $\beta \in(0,1)$. The period utility function $u(\cdot, \cdot)$ is assumed to be increasing in both arguments, concave, and to satisfy $u_{c m}>0$. In addition, we assume that $u$ satisfies assumptions (2) and (3).

Letting fiscal policy be Ricardian, the equilibrium dynamics of inflation and the nominal interest rate are governed by the discrete-time counterparts of the Taylor rule (10) and the equilibrium Euler equation (17), which are given, respectively, by

$$
1+R_{t}=\left(1+R^{*}\right)+\gamma\left(\pi_{t}-\pi^{*}\right)
$$

and

$$
L\left(R_{t}\right)=\beta L\left(R_{t+1}\right) \frac{1+R_{t}}{1+\pi_{t+1}}
$$

where $1+R^{*} \equiv\left(1+\pi^{*}\right) / \beta$. The function $L(\cdot)$ is implicitly given by the solution for $\lambda$ to the equilibrium conditions $\lambda=u_{c}(y, m)$ and $u_{m}(y, m) / u_{c}(y, m)=R /(1+R)$. The assumptions imposed on the period utility function imply that $L(R)>0, L^{\prime}(R)<0$ for all $R>0$, and $\lim _{R \rightarrow 0} L(R)=\infty$. We assume that the inflation coefficient of the Taylor rule satisfies $\beta \gamma>1$, so that the elasticity of the gross nominal interest rate with respect to gross inflation at the intended steady state is greater than one. Combining (24) and (25) yields the following first-order difference equation describing the equilibrium law of motion of $R_{t}:^{12}$

$$
L\left(R_{t}\right)=\beta L\left(R_{t+1}\right) \frac{1+R_{t}}{1+\pi^{*}+\gamma^{-1}\left(R_{t+1}-R^{*}\right)}
$$

This difference equation admits a unique constant solution given by $R_{t}=R^{*}$ for all $t$. This solution is therefore the unique steady-state equilibrium. Furthermore, this equilibrium is locally the unique perfect-foresight equilibrium. To see this, log-linearize (26) around $R^{*}$ to obtain:

$$
\widehat{R}_{t+1}=\left[\frac{\eta-R^{*} /\left(1+R^{*}\right)}{\eta-(\gamma \beta)^{-1} R^{*} /\left(1+R^{*}\right)}\right] \widehat{R}_{t}
$$

where $\widehat{R}_{t} \equiv \ln \left(R_{t} / R^{*}\right)$ denotes the log-deviation of $R_{t}$ from its intended steady-state value and $\eta \equiv L^{\prime}\left(R^{*}\right) R^{*} / L\left(R^{*}\right)<0$ denotes the steady-state elasticity of the marginal utility of

\footnotetext{
${ }^{12}$ This equation is the discrete-time version of (18).
} 
Figure 5: Phase diagram in the discrete-time model

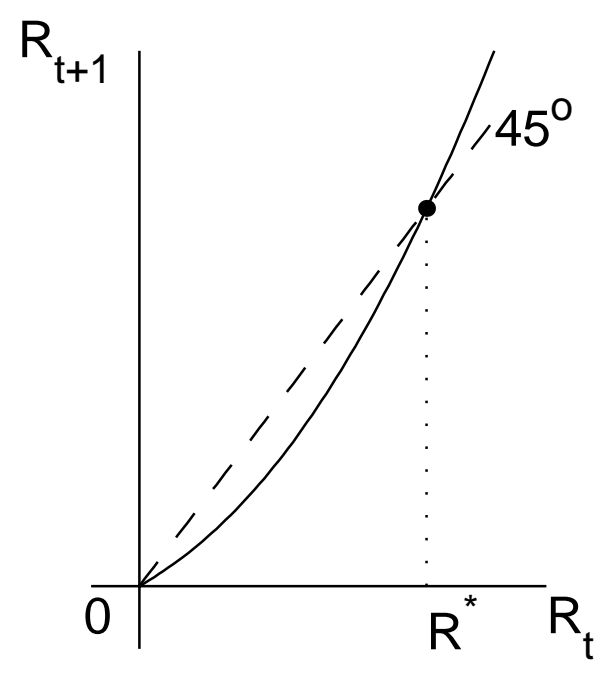

consumption with respect to the nominal interest rate. Because $\eta<0$ and $\beta \gamma>1$, we have that the coefficient in square brackets in the above expression is greater than 1 . It follows that the only solution to (26) that originates in a small neighborhood around $R^{*}$ and converges to it is $R^{*}$ itself.

But, as in the continuous-time case, the discrete-time economy under study admits other equilibria in which the nominal interest rate moves away from the intended steady state. Indeed, there exist liquidity traps in which the nominal interest rate converges to zero. To see why, note that because $L(R)$ converges to infinity as $R$ vanishes, equation (26) implies that if $R_{t}$ converges to zero, so does $R_{t+1}$. Figure 5 depicts the phase diagram associated with (26). The phase diagram crosses the $45^{\circ}$ line at $R_{t}=R^{*}$ from below. Also, for $R_{t} \in\left(0, R^{*}\right)$, the phase diagram is positive and lies below the $45^{\circ}$ line. Thus, sequences $\left\{R_{t}\right\}_{t=0}^{\infty}$ with $0<R_{0}<R^{*}$ converge monotonically to zero. Along such trajectories, inflation falls continuously, the real interest rate falls, and real balances increase without bounds.

\section{A Sticky-Price Model}

In this section we consider an economic environment with nominal rigidities. In addition, unlike in the flexible-price economy, in the model analyzed here product markets are imperfectly competitive and labor supply (and thus production) is endogenous. Price stickiness, production, and imperfect competition constitute three basic elements typically present in theoretical evaluations of the stabilizing properties of Taylor rules (e.g., Rotemberg and 
Woodford, 1999). Our goal continues to be to show that even in the absence of the zero bound on the interest-rate rule, that is, even if one believes that the monetary authority can credibly threaten to set a negative interest rate, liquidity traps may arise as equilibrium outcomes.

The economy is assumed to be populated by a continuum of household-firm units indexed by $j$ each of which produces a differentiated good $Y^{j}$. Firms have market power and set prices so as to maximize profits. The demand faced by firm $j$ is given by $Y^{d} d\left(P^{j} / P\right)$, where $Y^{d}$ denotes the level of aggregate demand, $P^{j}$ the price firm $j$ charges for the good it produces, and $P$ the aggregate price level. Such a demand function can be derived by assuming that households have preferences over a composite good that is produced from differentiated intermediate goods via a Dixit-Stiglitz production function. The function $d(\cdot)$ is assumed to be twice continuously differentiable, decreasing, and to satisfy $d(1)=1$ and $d^{\prime}(1)<-1 .{ }^{13}$

The production of good $j$ uses labor, $h^{j}$, supplied by household $j$ as the only input. For simplicity, we assume a linear technology:

$$
y\left(h^{j}\right)=h^{j}
$$

Following Rotemberg (1982), we assume that households face convex costs of adjusting prices. Specifically, the household's lifetime utility function is assumed to be of the form

$$
U^{j}=\int_{0}^{\infty} e^{-r t}\left[u\left(c^{j}, m^{j}\right)-z\left(h^{j}\right)-\frac{\theta}{2}\left(\frac{\dot{P}^{j}}{P^{j}}-\pi^{*}\right)^{2}\right] d t
$$

where $c^{j}$ denotes consumption of the composite good by household $j, m^{j} \equiv M^{j} / P$ denotes real money balances held by household $j$, and $M^{j}$ denotes nominal money balances. The utility function $u(\cdot, \cdot)$ is assumed to be increasing, twice continuously differentiable, weakly concave, and to satisfy $u_{c m}>0$ and assumptions (2) and (3). The function $z(\cdot)$ measures the disutility of labor and is assumed to be twice continuously differentiable, increasing, and strictly convex. The parameter $\theta$ measures the degree to which household-firm units dislike to deviate in their price-setting behavior from the target rate of inflation $\pi^{*}$.

Let $a^{j}$ denote the real value of the household $j$ 's financial wealth which consists of the sum of real money holdings and government bonds. Then $a^{j}$ evolves according to the following

\footnotetext{
${ }^{13}$ The restriction imposed on $d^{\prime}(1)$ is necessary for the firm's problem to be well defined in a symmetric equilibrium.
} 
law of motion:

$$
\dot{a}^{j}=(R-\pi) a^{j}-R m^{j}+\frac{P^{j}}{P} y\left(h^{j}\right)-\tau-c^{j} .
$$

Households are also subject to the following borrowing constraint that prevents them from engaging in Ponzi-type schemes:

$$
\lim _{t \rightarrow \infty} e^{-\int_{0}^{t}[R(s)-\pi(s)] d s} a^{j}(t) \geq 0
$$

Given the price firm $j$ charges for the good it produces, its sales are demand determined and equal to:

$$
y\left(h^{j}\right)=Y^{d} d\left(\frac{P^{j}}{P}\right) .
$$

Household $j$ chooses nonnegative functions of time for the control variables $c^{j}, m^{j}$, and $h^{j}$ and functions of time for the state variables $P^{j}$ and $a^{j}$ so as to maximize (27) subject to (28)-(30) taking as given $a^{j}(0), P^{j}(0)$, and the time paths of $\tau, R, Y^{d}$, and $P$. If the household's problem has an interior solution, then there exist functions of time $\lambda^{j}$ and $\mu^{j}$ such that the following conditions are satisfied:

$$
\begin{gathered}
u_{c}\left(c^{j}, m^{j}\right)=\lambda^{j} \\
u_{m}\left(c^{j}, m^{j}\right)=\lambda^{j} R \\
z^{\prime}\left(h^{j}\right)=\lambda^{j} \frac{P^{j}}{P} y^{\prime}\left(h^{j}\right)-\mu^{j} y^{\prime}\left(h^{j}\right) \\
\dot{\lambda}^{j}=\lambda^{j}(r+\pi-R) \\
\lambda^{j} \frac{P^{j}}{P} y\left(h^{j}\right)+\mu^{j} \frac{P^{j}}{P} Y^{d} d^{\prime}\left(\frac{P^{j}}{P}\right)=\theta r\left(\pi^{j}-\pi^{*}\right)-\theta \dot{\pi}^{j} \\
\lim _{t \rightarrow \infty} e^{-\int_{0}^{t}[R(s)-\pi(s)] d s} a^{j}(t)=0
\end{gathered}
$$


where $\pi^{j} \equiv \dot{P}^{j} / P^{j}$

\subsection{Equilibrium}

We assume that the government follows a globally active interest-rate feedback rule and a Ricardian fiscal policy as described in section 2.2. In a symmetric equilibrium all householdfirm units choose identical functions for consumption, asset holdings, and prices. Thus, we can drop the superscript $j$. In addition, the goods market must clear, that is,

$$
c=y(h)
$$

Combining equations (31) and (32) yields a liquidity preference function of the form

$$
m=m(c, R)
$$

Given our maintained assumption about the form of the instant utility index over consumption and real balances, the liquidity preference function (38) is increasing in consumption and decreasing in the nominal interest rate.

If $u(\cdot, \cdot)$ is strictly concave, then using (37) and (38) to eliminate $c$ and $m$ from (31) yields the following expression for $h$ :

$$
h=h(\lambda, R)
$$

where $h_{\lambda}<0, h_{R}<0 .{ }^{14}$ Let $\eta \equiv d^{\prime}(1)<-1$ denote the equilibrium price elasticity of the demand function faced by an individual firm. Using (10), (33), and (39) to eliminate $\mu, \pi$, and $h$ from equations (34) and (35) yields the following vector differential equation describing the equilibrium dynamics of $(\lambda, R)$ :

$$
\begin{aligned}
\dot{\lambda} & =\lambda\left(\gamma^{-1}-1\right)\left(R-R^{*}\right) \\
\dot{R} & =r\left(R-R^{*}\right)-\frac{h(\lambda, R) \lambda}{\theta \gamma}\left[1+\eta-\frac{\eta z^{\prime}(h(\lambda, R))}{\lambda}\right]
\end{aligned}
$$

A perfect-foresight equilibrium is a pair of functions $\{\lambda, R\}$ satisfying (40) and (41). Given the equilibrium functions $\{\lambda, R\}$, the corresponding equilibrium functions $\{h, c, \pi, m\}$ are uniquely determined by (39), (37), (10), and (38), respectively. The assumed Ricardian nature of the monetary-fiscal regime requires that the fiscal authority sets taxes in such a way that, given paths for $R, \pi$, and $m$ and an initial condition $a(0)$, the path for $a$ implied

\footnotetext{
${ }^{14}$ To see this, note that $h_{\lambda}=\left[u_{m m}-\left(u_{m} / u_{c}\right) u_{c m}\right] /\left[\left(u_{c c} u_{m m}-u_{c m}^{2}\right)\right]$ and that $h_{R}=-h_{\lambda} u_{c m} m_{R}$.
} 
by equation (19) satisfies the transversality condition (20).

\subsection{Steady-state equilibria}

A steady-state equilibrium is defined as a pair of constant functions $\{\lambda, R\}$ satisfying equations (40) and (41); that is,

$$
\begin{array}{r}
R=R^{*} \\
\frac{1+\eta}{\eta} \lambda=z^{\prime}\left(h\left(\lambda, R^{*}\right)\right)
\end{array}
$$

Recalling that $z(\cdot)$ is strictly convex, it follows from (42) and (43) that there exists a unique steady-state equilibrium $\left(\lambda^{*}, R^{*}\right)$. At the steady-state equilibrium the nominal interest rate takes its target value $R^{*}$. Aggregate output is such that firms equate marginal cost, given by $z^{\prime}(h) / \lambda$, to marginal revenue, $(1+\eta) / \eta{ }^{15}$ As in the flexible price case, the uniqueness of the steady-state equilibrium is a consequence of the assumption that the Taylor criterion is globally valid. Benhabib, Schmitt-Grohé, and Uribe (2000b) show that if the interest rate rule is restricted to be nonnegative, then at least two steady-state equilibria exist.

\subsection{Local equilibria}

We now consider perfect-foresight equilibria in which $\lambda$ and $R$ remain bounded in a small neighborhood around the steady state $\left(\lambda^{*}, R^{*}\right)$ and converge asymptotically to it. Linearizing equations (40) and (41) around $\left(\lambda^{*}, R^{*}\right)$, we obtain the system:

$$
\left(\begin{array}{c}
\dot{\lambda} \\
\dot{R}
\end{array}\right)=J\left(\begin{array}{c}
\lambda-\lambda^{*} \\
R-R^{*}
\end{array}\right)
$$

where

$$
\begin{aligned}
J= & {\left[\begin{array}{cc}
0 & u_{c}\left(\gamma^{-1}-1\right) \\
J_{21} & J_{22}
\end{array}\right] } \\
J_{21} & =\frac{y \eta}{\theta \gamma}\left[z^{\prime \prime} h_{\lambda}-\frac{z^{\prime}}{\lambda}\right]>0 \\
J_{22} & =r+\frac{y \eta}{\gamma \theta} z^{\prime \prime} h_{R}>0
\end{aligned}
$$

\footnotetext{
${ }^{15}$ Note that since $\eta$ is the elasticity of demand, $\eta /(1+\eta)$ represents the steady-state markup of prices over marginal cost. Because all firms set identical prices in equilibrium, the relative price of each good $j$ in terms of the composite consumption good (the numeraire) is unity.
} 
Because monetary policy is active $(\gamma>1)$, the trace and the determinant of $J$ are positive. This implies that both eigenvalues of $J$ have positive real parts. It then follows from the fact that both $\lambda$ and $R$ are jump variables that the equilibrium is locally determinate.

This result reproduces that basic message of a number of recent papers advocating the stabilizing properties of Taylor rules in the context of neo-Keynesian models like the one developed in this section (e.g., Clarida, Galí, and Gertler, 1997; Rotemberg and Woodford, 1997 and 1999, among others). However, by construction, this result is valid only if one restricts attention to equilibria in which endogenous variables remain forever bounded in an arbitrarily small neighborhood around the intended steady state. Benhabib, Schmitt-Grohé and Uribe (2000b) demonstrate that if the interest-rate rule is bounded below by zero, then a second steady state emerges. This second steady state is locally indeterminate and, as they argue, has all the essential characteristics of a liquidity trap. More importantly, there exist equilibrium trajectories emerging arbitrarily close to the intended steady-state that converge to the liquidity trap. When the monetary authority is assumed to be able to credibly commit to a globally active interest-rate rule, then the second, unintended steady state disappears. However, such commitment does not eliminate the risk of falling into a self-fulfilling liquidity trap. We turn to this issue next.

\subsection{Global equilibria}

To illustrate the existence of liquidity traps, we limit attention to a particular preference specification that implies interest rate dynamics identical to those arising in the flexible-price economy. Specifically, assume that $u(\cdot, \cdot)$ is homogeneous of degree one in $c$ and $m{ }^{16}$ In this case, equations (37), (38), and (31) taken together imply that in equilibrium the marginal utility of consumption is a decreasing function of the nominal interest rate alone. Thus, a relationship like (16) holds. ${ }^{17}$ The equilibrium dynamics are represented by the following planar system in $h$ and $R$ :

$$
\begin{gathered}
\dot{R}=\frac{L(R)}{L^{\prime}(R)}\left(\gamma^{-1}-1\right)\left(R-R^{*}\right) \\
{\left[r-\frac{L(R)}{L^{\prime}(R)}\left(\gamma^{-1}-1\right)\right]\left(R-R^{*}\right)=\frac{h L(R)}{\theta \gamma}\left[1+\eta-\frac{\eta z^{\prime}(h)}{L(R)}\right]}
\end{gathered}
$$

\footnotetext{
${ }^{16}$ The family of utility functions given in (4) belongs to this class if $\sigma=0$.

${ }^{17}$ To see why, note that in this case $u_{c}$ is homogeneous of degree zero in $c$ and $m$, and the liquidity preference function is linear in consumption.
} 
Figure 6: The liquidity trap in the sticky-price model
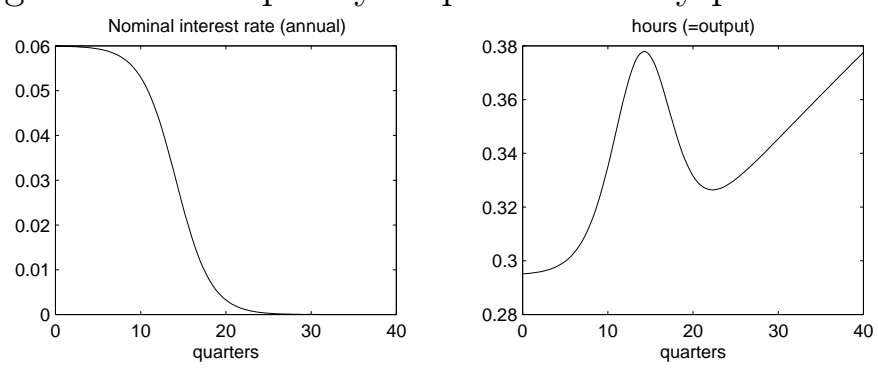

If $L(\cdot)$ satisfies assumption (21), then the scalar system (45) has a phase diagram like the one depicted in figure 3. In this case, there exists a continuum of trajectories for the nominal interest rate that satisfy equation (45) and converge to 0 . These trajectories represent equilibrium allocations if they imply, by the static equation (46), trajectories for $h$ that are feasible.

Consider the special case that $u(c, m)$ takes the Cobb-Douglas form $c^{1-b} m^{b}$. Then $L(R) / L^{\prime}(R)=-R / b$, which converges to zero as $R$ vanishes. Equation (45) becomes $\dot{R}=R\left(R-R^{*}\right)\left(1-\gamma^{-1}\right) / b$. The solution to this differential equation is $R(t)=\left[1 / R^{*}+\right.$ $\left.\exp \left[R^{*}\left(\gamma^{-1}-1\right) / b\right]\left(1 / R(0)-1 / R^{*}\right)\right]^{-1}$. It is easy to verify that for any $0<R(0)<R^{*}, R(t)$ is strictly positive and converges asymptotically to zero. In general it is difficult to establish that given a function $R$ that solves (45), the function $h$ implied by (46) is well defined. Here we limit our discussion to a parameterized example in which $z(h)=\rho \ln (1-h)$, with $h \in[0,1)$. Under this assumption, (46) is a second-order polynomial in $h$, whose coefficients are functions of $R$ (and are therefore time varying). Figure 6 depicts the equilibrium dynamics of the nominal interest rate and hours associated with an initial value of $R$ less than the intended steady state $R^{*}{ }^{18}$ The graph shows that a liquidity trap exists, that is, there exist equilibrium trajectories in which the nominal interest rate converges to zero. In addition, inflation keeps falling despite the central bank's efforts to stimulate the economy through low real rates. In the parameterized example, leisure converges to zero as the economy approaches the liquidity trap. The reason for this lies in the behavior of the representative household's labor supply schedule. With the decline in nominal rates, real balances increase.

\footnotetext{
${ }^{18}$ The parameter values used to compute the equilibrium dynamics are as follows: The time unit is one quarter. The intended nominal interest rate is 6 percent per year, which corresponds to the average yield on 3-month T-bills over the period 1960:Q1 to 1998:Q3. We set the target rate of inflation at 4.2 percent per year. This number matches the average growth rate of the U.S. GDP deflator during 1960:Q1-1998:Q3. Following Taylor (1993), we set the slope of the interest rate rule at the intended steady state equal to 1.5 . To calibrate $b$, we use the liquidity preference function given by (38), which in the Cobb-Douglas case takes the form $m=b /(1-b) y / R$, to express $b$ as the following function of the nominal interest rate and money velocity: $b=R /(R+y / m)$. In the U.S. economy, average annual M1 velocity over the period 1960:Q11999:Q4 was 5.8. This figure together with the assumed value for $R^{*}$ implies $b=0.0102$. We assign a value to the preference parameter $\rho$ such that in steady state households spend one third of their time working.
} 
The increase in real balances is so strong that it increases the marginal utility of income and in this way shifts the household's labor supply schedule out.

\section{Conclusion}

This paper contributes to a recent literature that evaluates the consequences of active interest-rate feedback rules from a global perspective. Specifically, the paper builds on a key result derived by Benhabib, Schmitt-Grohé, and Uribe (2000b). Namely, that Taylor rules in combination with a zero bound on nominal interest rates give room to unintended deflationary spirals. The present study shows that the zero bound itself is not at the root of the problem. For a number of standard model specifications, liquidity traps emerge even if the government can commit to a globally active interest rate rule; that is, even if the government can credibly threaten to set a negative interest rate at low enough rates of inflation.

An important immediate issue that arises from the results of this paper is how to avoid liquidity traps while maintaining the desirable local properties of Taylor rules. Benhabib, Schmitt-Grohé, and Uribe (2000c) and Woodford (1999, 2000) provide examples of policies capable of eliminating liquidity traps when the Taylor rule is assumed to satisfy the zero bound. The essence of their proposals is to build a fiscal regime whereby the government embarks in aggressive fiscal expansions in the event that the economy slips into a liquidity trap. This emergency fiscal policy must be aggressive enough so that near the unintended steady state total government liabilities grow at a rate larger than the nominal interest rate. It follows that under such fiscal policy, in the event of a liquidity trap, total government liabilities grow without bounds in present discounted value. Equivalently, private agents would find themselves holding long-run asset positions of positive present discounted value, which is inconsistent with optimizing behavior if consumption and real money holdings are to be finite at each point in time. Because such a situation can not be supported as an equilibrium outcome, the suggested policies effectively rule out self-fulfilling liquidity traps.

Clearly, the proposals for avoiding liquidity traps contained in Benhabib, Schmitt-Grohé and Uribe (2000c) and in Woodford (1999, 2000) will also be effective when the Taylor rule is globally active. Specifically, any fiscal policy that guarantees that total government liabilities

grow at all times at a rate lower than the target nominal rate and bounded away from zero will eliminate self-fulfilling liquidity traps and ensure the global uniqueness of the intended equilibrium. 


\section{References}

Benhabib, Jess, Stephanie Schmitt-Grohé, and Martín Uribe "Monetary Policy and Multiple Equilibria," 2000a, forthcoming American Economic Review [also available at http://www. econ. upenn.edu/ ${ }^{\sim}$ uribe].

Benhabib, Jess, Stephanie Schmitt-Grohé, and Martín Uribe "The Perils of Taylor Rules," 2000b, forthcoming Journal of Economic Theory [also available at http://www. econ.upenn.edu/ ${ }^{\sim}$ uribe].

Benhabib, Jess, Stephanie Schmitt-Grohé, and Martín Uribe "Avoiding Liquidity Traps," 2000c, unpublished, University of Pennsylvania [also available at http://www. econ.upenn.edu/ ${ }^{\sim}$ uribe].

Buiter, Willem H. "The Young Person's Guide to Neutrality, Price Level Indeterminacy, Interest Rate Pegs, and Fiscal Theories of the Price Level," NBER working paper No. 6396, February 1998.

Buiter, Willem H. "The Fallacy of the Fiscal Theory of the Price Level," NBER working paper No. 7302, August 1999.

Carlstrom, Charles T. and Timothy Fuerst "Real Indeterminacy in Monetary Models With Nominal Interest Rate Distortions," unpublished, Federal Reserve Bank of Cleveland, 2000.

Clarida, Richard, Jordi Galí, and Mark Gertler "Monetary Policy Rules and Macroeconomic Stability: Evidence and Some Theory," 1997, NBER working paper No. 6442.

Clarida, Richard, Jordi Galí, and Mark Gertler, "Monetary policy rules in practice: some international evidence," European Economic Review, 42, (1998): 1033-1067.

Dupor, Bill "Investment and Interest Rate Policy," unpublished, University of Pennsylvania, October 1999.

Leeper, Eric, "Equilibria under 'Active' and 'Passive' Monetary and Fiscal Policies," Journal of Monetary Economics, 27, (1991): 129-147.

Levin, Andrew, Volker Wieland, and John Williams "Robustness of Simple Policy Rules Under Model Uncertainty" In Monetary Policy Rules, edited by John B. Taylor, University of Chicago Press, 1999: 263-299.

Lucas, Robert E. Jr. and Nancy Stokey, "Money and Interest in a Cash-in-Advance Economy," Econometrica, 55, (1987): 491-514.

Orphanides, Athanasios "Monetary Policy Rules Based on Real-Time Data," Finance and Economic Discussion Series No. 1998-03, Federal Reserve Board, 1997.

Rotemberg, Julio J., "Sticky prices in the United States," J. Polit. Econ., 90, (1982): 11871211. 
Rotemberg, Julio and Woodford, Michael "Interest Rate Rules in an Estimated Sticky Price Model" In Monetary Policy Rules, edited by John B. Taylor, University of Chicago Press, 1999: 57-119.

Sack, Brian "Uncertainty, Learning, and Gradual Monetary Policy," unpublished, Board of Governors of the Federal Reserve System, July 1998.

Schmitt-Grohé, Stephanie and Martín Uribe, "Price Level Determinacy and Monetary Policy Under a Balanced-Budget Requirement," Journal of Monetary Economics, 45, (February 2000): 211-246.

Taylor, John B., "Discretion versus rules in practice," Carnegie-Rochester Series on Public Policy, 39, (1993): 195-214.

Taylor, John B. "A Historical Analysis of Monetary Policy Rules" In Monetary Policy Rules, edited by John B. Taylor, University of Chicago Press, 1999: 319-341.

Woodford, Michael "Control of the Public Debt: A Requirement for Price Stability?," NBER working paper No., 5680/ July 1996.

Woodford, Michael "Price-Level Determination under Interest-Rate Rules," unpublished, Princeton University, April 1999.

Woodford, Michael "Fiscal Requirements for Price Stability," unpublished, Princeton University, May 2000. 